Original Research Paper

\title{
Proyek di Desa Pendampingan Mahadesa untuk Sosialisasi TDC (Trade \& Distribution Center) Desa Labuhan Haji
} \author{
Yudha Aryadi Zuhal ${ }^{2}$, Sahrol Laeli ${ }^{3}$, Hikmayatur Rohmi ${ }^{4}$, Rahmat Lutfian Hadi ${ }^{5}$, Nurul Walida ${ }^{5}$ \\ ${ }^{1}$ Fakultas Matematika dan Ilmu Pengetahuan Alam Universitas Mataram, Mataram, Indonesia \\ ${ }^{2}$ Fakultas Teknik Universitas Mataram, Mataram, Indonesia \\ ${ }^{3}$ Fakultas Hukum Universitas Mataram, Mataram, Indonesia \\ ${ }^{4}$ Fakultas Teknologi Pangan, Universitas Mataram, Mataram, Indonesia \\ ${ }^{5}$ Fakultas Ilmu Sosial dan Politik, Universitas Mataram, Mataram, Indonesia
}

Ahmad Jupri ${ }^{1}$, Eka S. Prasedya ${ }^{1}$, Muhammad Firman Azima ${ }^{1}$, Fajar Maulana Dwi Praja ${ }^{2}$, Wisnu Rizaldy ${ }^{2}$,

DOI: https://doi.org/10.29303/jpmpi.v4i2.693

Sitasi: Jupri, A., Prasedya, E. S., Azima, M. F.., Praja, F. M. D., Rizaldy, W., Zuhal, Y. A., Laeli, S., Rohmi, H., Hadi, R. L., \& Walida, N. (2021). Proyek di Desa Pendampingan Mahadesa untuk Sosialisasi TDC (Trade \& Distribution Center) Desa Labuhan Haji. Jurnal Pengabdian Magister Pendidikan IPA, 4(1)

\section{Article history}

Received: 03 Januari 2021

Revised: 08 Maret 2021

Accepted: 29 Maret 2021

*Corresponding Author:

Ahmad Jupri, 1Fakultas

Matematika dan Ilmu

Pengetahuan Alam Universitas

Mataram, Mataram, Indonesia;

Email: juprizikril@gmail.com

\begin{abstract}
Program KKN Tematik di Era New Normal merupakan salah satu bentuk pengabdian kepada masyarakat yang dilakukan oleh mahasiswa dan dibimbing oleh dosen sebagai salah satu wujud implementasi Tri Dharma Perguruan Tinggi. Pelaksanaan kegiatannya dalam masa pandemi Covid-19 maka selalu memperhatikan protokol kesehatan disetiap kegiatan. Program kerja utama dalam KKN bertema Mahadesa ini adalah sosialisasi mengenai program Mahadesa TDC (Trade Distribution Center) yang merupakan hasil kerjasama antara pemerintah Provinsi NTB dengan Badan Usaha Milik Daerah (BUMD) PT. GNE. Secara umum, program TDC (Trade Distribution Center) ini merupakan suatu sistem pemasaran terintegrasi (integrated marketing) berbasis digital. Desa Labuhan Haji adalah salah satu dari sekian banyak desa di Kecamatan Labuhan Haji, Kabupaten Lombok Timur, NTB yang sektor ekonominya terdampak pandemi Covid19, khususnya UMKM dan pedagang warung. Sistem perdagangan berbasis teknologi digital ini diharapkan menjadi jembatan agar produk UMKM di Desa Labuhan Haji dapat mengakses pasar digital. Sehingga dapat mengurangi permasalahan di bidang ekonomi desa seperti dalam pendistribusian produk-produk UMKM desa, yang lingkup pendistribusiannya terbatas.
\end{abstract}

Keywords: KKN Tematik; New Normal; TDC.

\section{Pendahuluan}

Program KKN Tematik di Era New Normal merupakan salah satu bentuk pengabdian kepada masyarakat yang dilakukan oleh mahasiswa sebagai salah satu wujud implementasi Tri Dharma Perguruan Tinggi, yang dipadukan pelaksanaan manajemen dan waktunya dengan kegiatan yang selalu memperhatikan protokol kesehatan disetiap kegiatan. KKN Tematik sebagai proses pembelajaran bagi mahasiswa sekaligus wahana pemberdayaan masyarakat. KKN Tematik ini direncanakan, dan dilaksanakan secara sistematis berdasarkan tema yang digali dari potensi masyarakat, dirumuskan, dan dilaksanakan bersama masyarakat. Hal ini diharapkan dapat memacu kemampuan masyarakat dalam pengembangan diri dan wilayah sehingga kesejahteraannya meningkat.

Program Kuliah Kerja Nyata (KKN) yang bertemakan Mahadesa merupakan sebuah program infrastruktur ekonomi digital terintegrasi di NTB 
dalam mewujudkan sistem perdagangan berbasis teknologi digital di NTB. Sistem perdagangan ini diharapkan menjadi jembatan agar produk UMKM di NTB mudah mengakses pasar digital. Sehingga dapat mengurangi permasalahan di bidang ekonomi desa seperti dalam pendistribusian produk-produk UMKM desa, yang lingkup pendistribusiannya terbatas.

Tempat yang dijadikan lokasi pengabdian mahasiswa KKN adalah Desa Labuhan Haji, Kecamatan Labuhan Haji, Kabupaten Lombok Timur, NTB. Labuhan Haji adalah salah satu desa yang terletak di Kecamatan Labuhan Haji, Kabupaten Lombok Timur, Provinsi Nusa Tenggara Barat. Batas wilayah Desa Labuhan Haji yaitu Desa Suyawang di sebelah utara, desa Kertasari di sebelah selatan, Selat Alas di sebelah timur, serta Desa Peneda Gandor di sebelah barat. Nama Desa Labuhan Haji sendiri diambil pada era penduduk Belanda dan Jepang, masyarakat Lombok memanfaatkan pelabuhan yang ada sebagai tempat awal berangkat untuk menunaikan ibadah haji. Selain digunakan sebagai pelabuhan keberangkatan ibadah haji, pelabuhan ini juga berfungsi sebagai pintu masuk para pedagang Cina ke wilayah Lombok.

Desa Labuhan Haji merupakan satusatunya desa di Kecamatan Labuhan Haji yang tidak pernah mengalami pemekaran, hal ini yang menyebabkan desa Labuhan Haji memiliki daerah yang cukup luas sebesar 396,85 Ha yang terdiri dari tanah sawah, tanah kering, tanah basah, tanah perkebunan, fasilitas umum, serta tanah hutan. Selain itu, mata pencaharian masyarakat Desa Labuhan Haji sangatlah beragam mulai dari bidang pertanian, perkebunan, peternakan, kerajinan, industry kecil, menengah, dan besar, serta jasa dan perdagangan.

Sejak tahun 2001, Desa Labuhan Haji telah resmi sebagai suatu Desa dengan wilayah pemerintahan desanya meliputi 9 (sembilan) dusun, yaitu:

1) Dusun Esot

2) Dusun Gelumpang

3) Dusun Sisik

4) Dusun Labuaji

5) Dusun Paok Pampang

6) Dusun Ambengan

7) Dusun Mandar

8) Dusun Montong Meong

9) Dusun Dasan Baru
Desa Labuhan Haji adalah salah satu dari sekian banyak desa di Kecamatan Labuhan Haji yang sektor ekonominya terdampak pandemi Covid-19. Banyak masyarakat mengeluh akan sulitnya perekonomian di masa pandemi Covid-19, khususnya UMKM dan pedagang warung yang mengeluhkan barang dagangannya tidak laku terjual karena keadaan pandemi yang mengharuskan orang-orang untuk berada di rumah.

Berdasarkan permasalahan di atas, maka diperlukan inovasi supaya distribusi produk-produk UMKM menjadi lancar dan mudah diakses. Oleh karena itu KKN tematik ini dengan tema Mahadesa bertujuan untuk memberdayakan desa secara ekonomi, memudahkan masyarakat mendapatkan berbagai jenis kebutuhannya tanpa harus keluar rumah, dengan pemesanan yang dilakukan melalui sistem di perangkat ponselnya melalui program TDC (Trade Distribution Center) yang nantinya akan bekerja sama dengan BUMDes dan beberapa lembaga desa lainya.

\section{Metode}

Metode penelitian ini terbagi ke beberapa bagian yaitu:

\section{1) Metode Observasi}

Metode observasi atau pengamatan adalah alat pengumpulan data yang dilakukan dengan cara mengamati dan mencatat secara sistematik gejalagejala yang ada di tempat penelitian (Newman, 2013). Pada metode pengamatan ini, penulis terjun langsung untuk mengamati secara langsung terhadap pelaksanaan KKN, kegiatan-kegiatan dan fenomena-fenomena sosial yang terjadi sebagai dampak dari pelaksanaan KKN yang diterapkan. Data yang diperlukan dalam metode pengamatan ini adalah mengamati secara langsung di lokasi (Mason, 2002).

\section{2) Metode Interview}

Metode ini disebut juga dengan metode wawancara, yaitu suatu metode pengumpulan data yang dilakukan melalui tanya jawab secara langsung dengan sumber (Merriam, 2015). Interview merupakan alat pengumpulan informasi dengan cara mengajukan pertanyaan secara lisan, untuk dijawab secara lisan juga, ciri utama dari interview adalah kontak langsung dengan tatap muka antara pencari informasi dengan sumber informasi (Taylor, 2016). Wawancara secara 
mendalam ini dilakukan oleh peneliti terhadap informan yang menjadi obyek dari penelitian ini yaitu kepala dusun, PKK, PEMDes dan BUMDes serta Karang Taruna Desa Labuhan Haji. Wawancara ini bertujuan untuk memperoleh informasi yang ada relevansinya dengan pokok persoalan penelitian di Desa Labuhan Haji.

\section{3) Metode Dokumentasi}

Dalam penelitian kualitatif terdapat sumber data yang berasal dari manusia seperti dokumen berupa foto dan bahan statistik (Fathoni, 2006). Metode dokumentasi ini merupakan salah satu bentuk pengumpulan data yang paling mudah. Dokumen yang diperlukan dalam penelitian ini meliputi kepala dusun, PKK, PEMDes dan BUMDes serta Karang Taruna Desa Labuhan Haji. Adapun data-data lain yang dibutuhkan untuk melengkapi penyusunan laporan ini seperti dokumentasi dalam penelitian KKN.

Seluruh rangkaian kegiatan dilakukan melalui beberapa tahap seperti tahap persiapan, sosialisasi program, serta evaluasi dan monitoring.

\section{1) Tahap Persiapan}

Sebelum memulai kegiatan KKN, disiapkan terlebih dahulu surat pengantar KKN dan izin kepada kepala desa untuk melakukan kegiatan KKN di Desa Labuhan Haji. Secara umum ada 2 (dua) program wajib yang akan dilaksanakan oleh mahasiswa selama KKN yaitu sosialisasi dan pematangan atau pemantapan program Mahadesa. Selain itu, ada beberapa program kerja tambahan yang akan dilakukan Dengan adanya kedua program tersebut diharapkan kegiatan KKN dapat terlaksana dengan baik dan memberikan manfaat bagi desa dan masyarakatnya.

\section{2) Sosialisasi Program}

Kegiatan sosialisasi ditargetkan pada seluruh lapisan masyarakat. Pada kegiatan tersebut kami akan menjelaskan maksud dan tujuan pelaksanaan kegiatan serta memperkenalkan metode dan media yang digunakan dalam kegiatan tersebut. Misalnya brosur/ pamflet dan spanduk kegiatan.

\section{3) Monitoring}

Dilakukan dengan cara mengecek apakah program sosialisasi yang dilakukan berjalan atau tidak dengan cara berkunjung ke desa tempat sosialisasi dalam kurun 3 pekan setelah tahap sosialisasi.

\section{Hasil dan Pembahasan}

Program kerja utama dalam KKN (Kuliah Kerja Nyata) tematik Desa Labuhan Haji era new normal ini adalah sosialisasi mengenai program Mahadesa TDC (Trade Distribution Center) yang merupakan hasil kerjasama antara pemerintah Provinsi NTB dengan Badan Usaha Milik Daerah (BUMD) PT. GNE (Muhammad, 2020). Secara umum, program TDC (Trade Distribution Center) ini merupakan suatu sistem pemasaran terintegrasi (integrated marketing) berbasis digital (Muhammad, 2020). Melalui program Mahadesa, UMKM akan dikembangkan melalui rantai bisnis pemberdayaan desa secara ekonomi dan masyarakat mendapatkan berbagai jenis kebutuhannya tanpa harus keluar rumah.

Pemesanan kebutuhan, dilakukan melalui sistem di perangkat ponselnya atau serba teknologi. BUMDes dalam hal ini dilibatkan sebagai ujung tombak, sekaligus sebagai fasilitator yang akan merekap dan memenuhi pesanan rumah tangga (masyarakat). Masyarakat berbelanja layaknya ke ritel modern, cukup hanya dari rumah melalui fasilitas Mahadesa ini.

Sistem bisnis yang dikembangkan GNE dalam program Mahadesa ini yaitu dengan memanfaatkan seluruh BUMDes sebagai perpanjangan tangan untuk melakukan pendataan kebutuhan masing-masing rumah tangga. Kebutuhan tersebut misalnya, sabun, odol, minyak goreng, beras dan sejeninya yang ada di catalog.

Masyarakat akan mendapatkan kemudahan berbelanja. BUMDes akan dapat keuntungan sebesar 70 persen dari total keuntungan. Rantai ekonomi dan bisnis dari tingkat provinsi, kabupaten/kota kemudian ke desa dan kelurahan akan terbangun kuat. Dan sama-sama akan mendapatkan manfaat ekonomi (keuntungan).

Program ini selain memperkuat infrastruktur perekonomian di desa, juga diharapkan mampu mengangkat berbagai produk IKM/UKM lokal untuk bisa bersaing, tidak hanya menjadi tuan di negerinya sendiri, tetapi juga dipasar nasional dan global.

PT. GNE dengan program TDC Mahadesanya saat in sudah menggeliat dengan pemberdayaan dan peningkatan ekonomi dari desa. 
Pemerintah di tingkat pusat, provinsi dan kabupaten saat ini sangat konsen menjadikan desa sebagai pusat ekonomi yang akan langsung menunjang kemajuan ekonomi merata di tingkat masyarakat desa. GNE dengan Mahadesanya sudah mulai dan terus berupaya menciptakan kolaborasi dalam pembangunan TDC Mahadesa di setiap desa yang ada di wilayah NTB. Saat ini telah terbangun TDC Mahadesa di 25 desa di wilayah kabupaten Lombok Barat yang digunakan sebagai role model pengembangan dan pemberdayaan ekonomi desa. GNE berkolaborasi dengan Bumdes menggunakan sentuhan teknologi kekinian untuk menciptakan nilai lebih. Bumdes saat ini sudah resmi mempunyai badan hukum yang kedepannya bisa membuat PT yang sesuai tertuang dalam UU nomor 11 tahun 2020 tentang cipta kerja tepatnya dibagian ke 10 yaitu pasal 117 (Muhammad, 2020).

Pemberdayaan pemuda dan dasawisma menjadi salah satu solusi untuk mengurangi angka pengangguran yang menjadi permasalahan nasional hari ini. TDC Mahadesa merupakan salah satu upaya menciptakan peluang kerja serta pemberdayaan yang berkelanjutan. TDC Mahadesa bukan hanya menyediakan bahan kebutuan seharihari tapi sudah mulai dengan pelayanan perbankan. Sinergi dan kolaborasi merupakan ruh untuk bersama-sama membangun ekonomi dari desa baik ditingkat pusat, provinsi, kabupaten, swasta dengan satu visi dan misinya yang sama untuk mewujudkan ekonomi NTB yang Gemilang. Berikut merupakan kegiatan sosialisasi program Mahadesa TDC (Trade Distribution Center) yang telah di lakukan di Desa Labuhan Haji:

\section{1) Sosialisasi Pemdes \& Bumdes Mengenai TDC (Trade Distribution Center)}

Pada tanggal 18 Januari 2021 telah dilakukan sosialisasi awal kepada Pemdes dan Bumdes mengenai program Mahadesa TDC di aula kantor Desa Labuhan Haji yang dihadiri oleh beberapa orang saja seperti kepala desa beserta jajarannya dan semua kepala dusun yang ada di Desa Labuhan Haji dengan tetap menerapkan protokol kesehatan 3M (memakai masker, menjaga jarak, dan mencuci tangan). Tujuan dilakukannya sosialisasi awal ini adalah agar Pemdes dan Bumdes mengetahui pengertian dan tujuan dasar dari program TDC ini. Kegiatan ini berjalan dengan lancar dimana kegiatan sosialisasi lanjutan akan dilakukan pada setiap masyarakat di dusun yang ada di Desa Labuhan Haji.

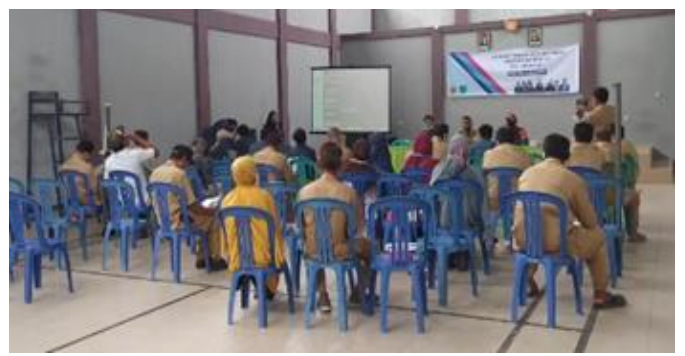

Gambar 1. Sosialiasi Awal TDC Pada Pemdes dan Bumdes

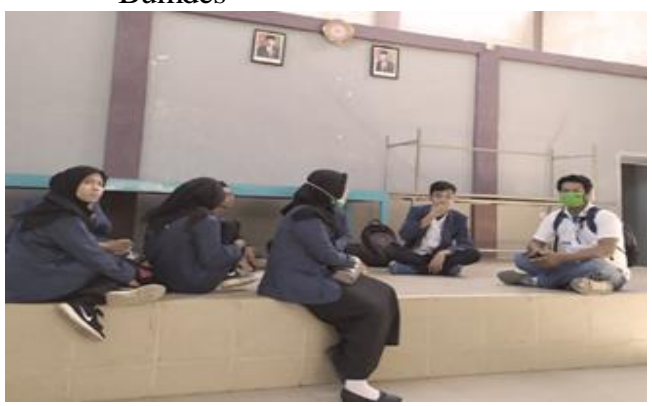

Gambar 2. Sosialiasi Awal TDC Pada Pemdes dan Bumdes

\section{2) Sosialisasi TDC di 9 Dusun Desa Labuhan Haji}

Menindak lanjuti kegiatan sosialisasi awal program TDC pada Pemdes dan Bumdes selanjutnya dilakukan sosialisasi program TDC pada masyarakat di dusun-dusun yang ada di Desa Labuhan Haji. Kegiatan sosialisasi di setiap dusun dihadiri oleh beberapa masyarakat saja mengingat dengan kondisi new normal yang harus memberlakukan 3M (memakai masker, menjaga jarak, dan mencuci tangan). Kegiatan sosialisasi program TDC di setiap dusun disambut dengan baik oleh masyarakat bahkan diharapkan program TDC ini agar segera terlaksana di Desa Labuhan Haji.

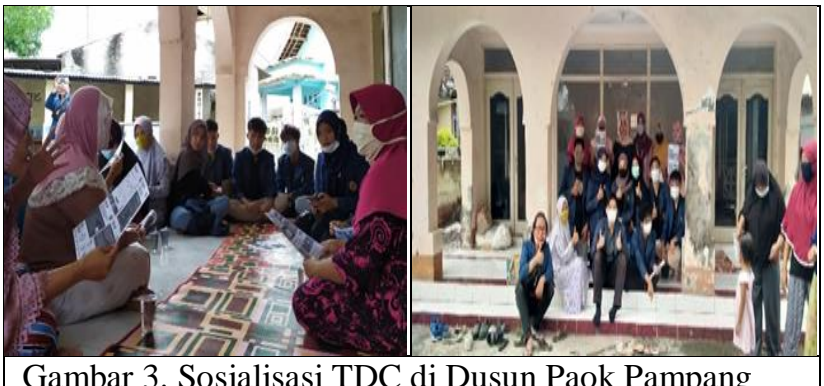

Gambar 3. Sosialisasi TDC di Dusun Paok Pampang 

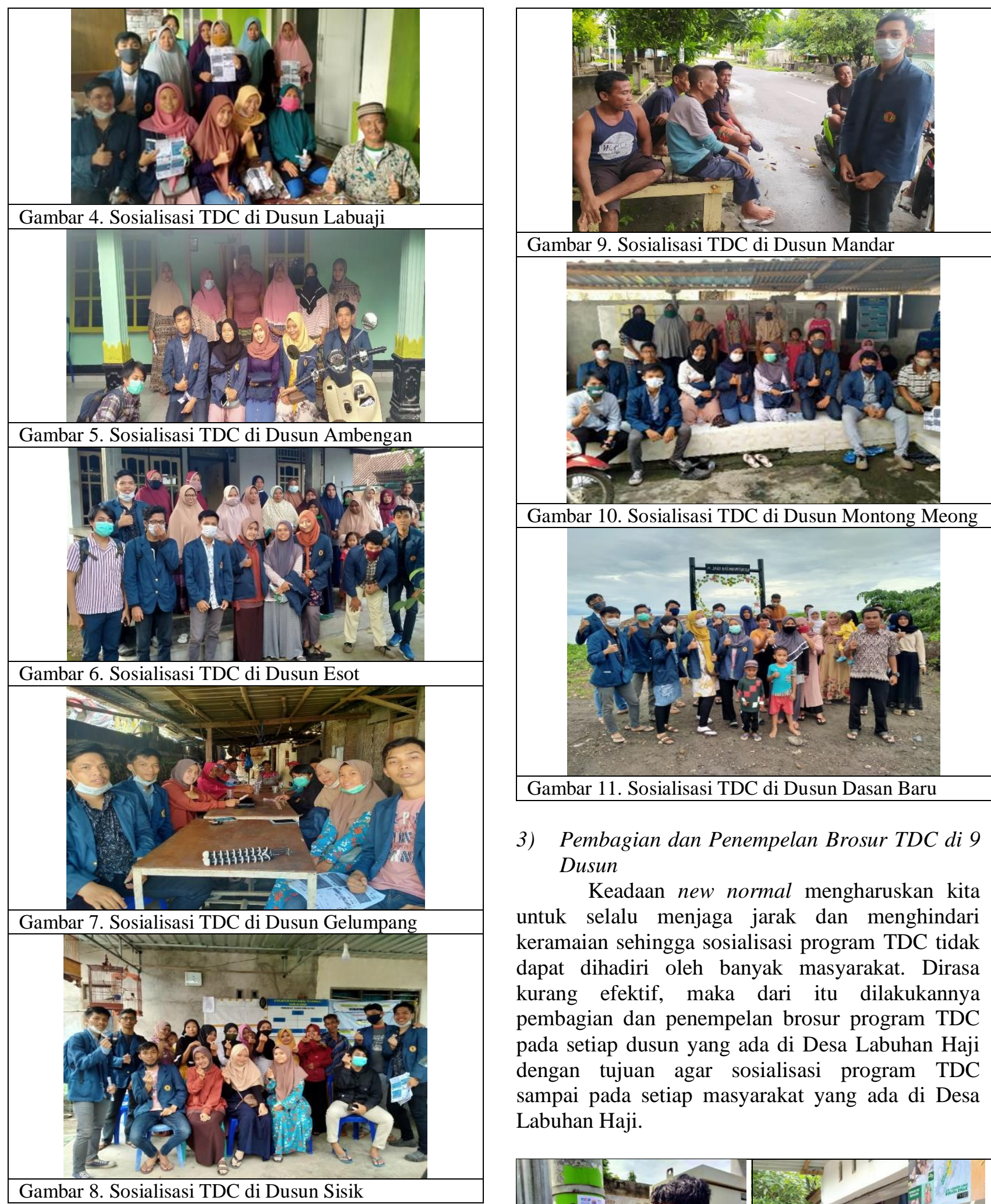

\section{3) Pembagian dan Penempelan Brosur TDC di 9 Dusun}

Keadaan new normal mengharuskan kita untuk selalu menjaga jarak dan menghindari keramaian sehingga sosialisasi program TDC tidak dapat dihadiri oleh banyak masyarakat. Dirasa kurang efektif, maka dari itu dilakukannya pembagian dan penempelan brosur program TDC pada setiap dusun yang ada di Desa Labuhan Haji dengan tujuan agar sosialisasi program TDC sampai pada setiap masyarakat yang ada di Desa Labuhan Haji.

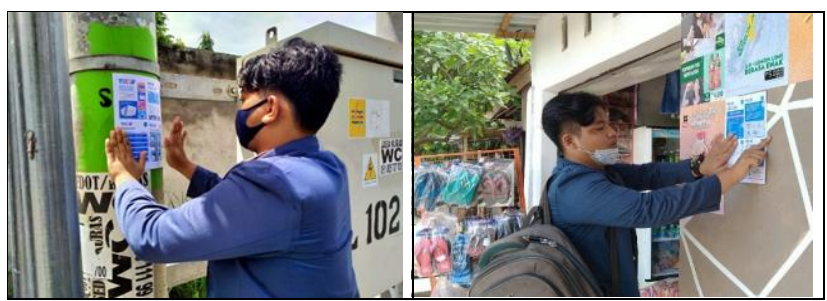




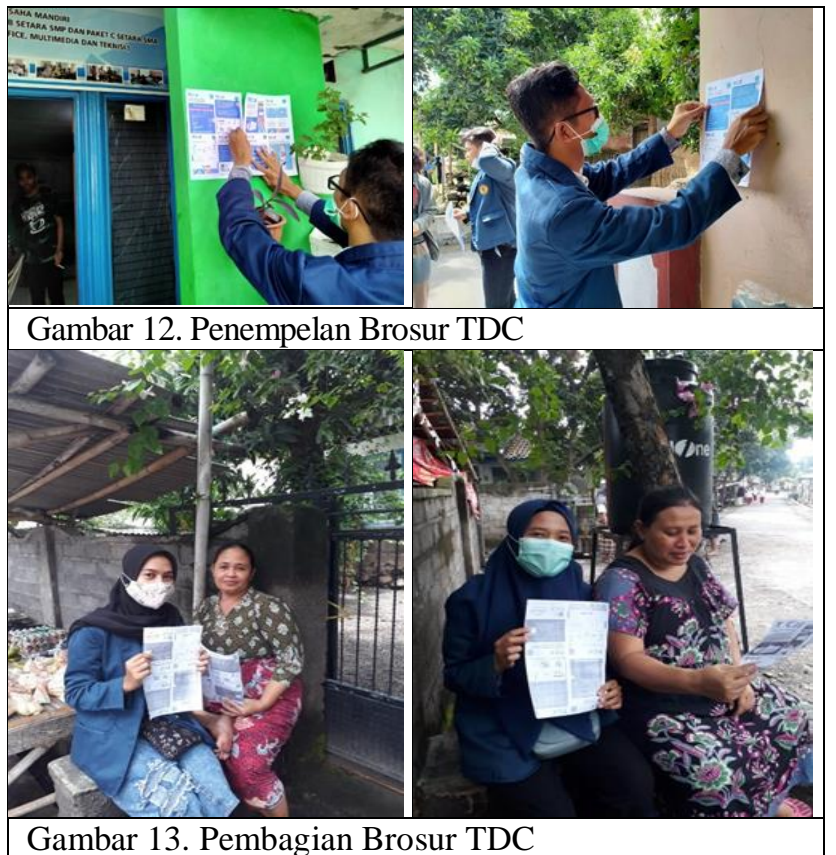

Selain melakukan program kerja utama yaitu sosialisasi mengenai program Mahadesa TDC (Trade Distribution Center), dilakukannya juga program kerja tambahan sebagai berikut.

\section{1) Mengajar Mengaji di $T P Q$ Ambengan dan $T P Q$ Esot}

Dilakukannya kegiatan mengajar mengaji anak-anak pada TPQ di Dusun Ambengan setiap hari Senin, Selasa, Kamis, Sabtu, dan Minggu. Selain itu, dilakukan juga kegiatan mengajar mengaji anak-anak pada TPQ di Dusun Esot setiap hari Rabu dan Jumat. Kegiatan ini dilakukan dengan tujuan agar anak-anak semangat dalam belajar mengaji atau membaca Al-Qur'an sehingga kelak dapat diterapkan dan menjadi keseharian dalam kehidupan.

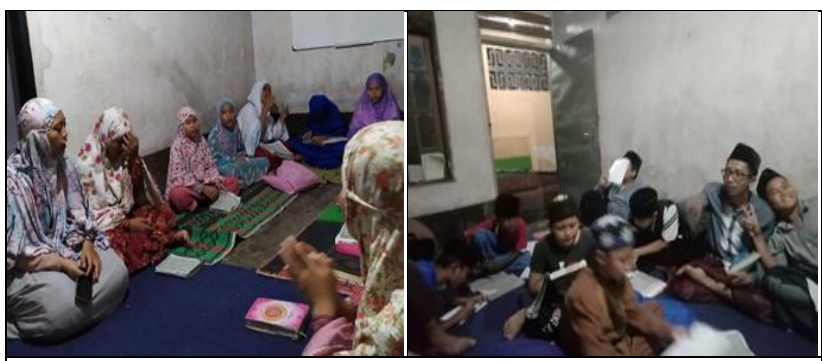

Gambar 14. Mengajar Mengaji di TPQ Ambengan

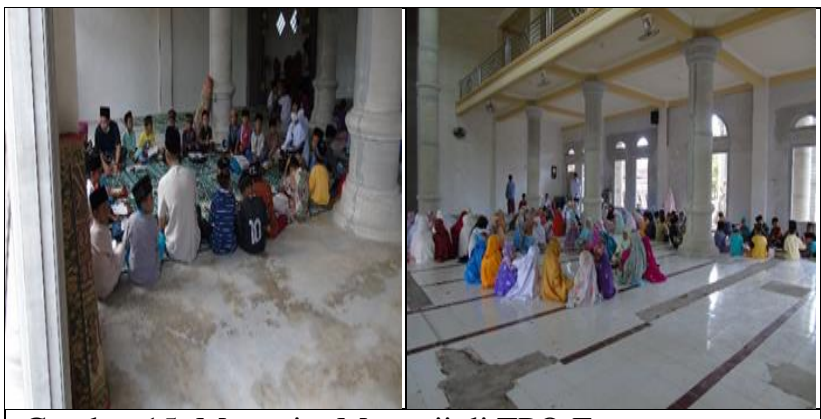

Gambar 15. Mengajar Mengaji di TPQ Esot

\section{2) Mengadakan Lomba di TPQ Ambengan}

Pada minggu terakhir mengajar mengaji, diadakannya kegiatan lomba praktik sholat, hafalan surat pendek, adzan, dan cerdas cermat tajwid di TPQ Ambengan. Kegiatan ini dilakukan sebagai bentuk luaran dari kegiatan mengajar mengaji serta sebagai bentuk apresiasi kepada anak-anak di TPQ Ambengan yang selalu bersemangat untuk belajar mengaji atau membaca Al-Qur'an.

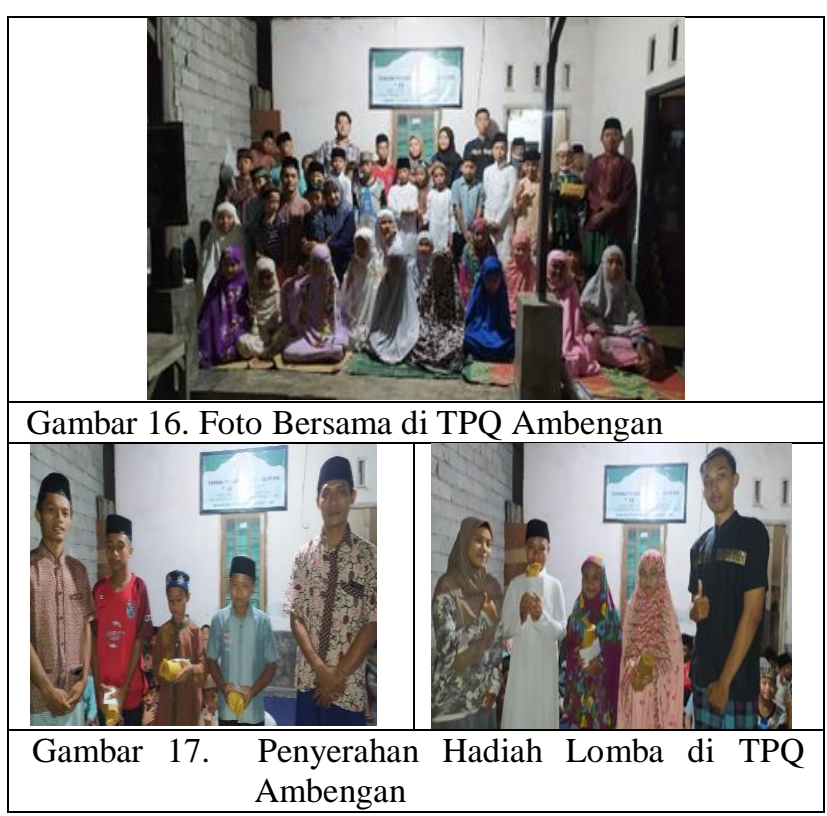

\section{3) Jumat 2B (Bebersih-Berbagi)}

Mengingat kondisi dengan keadaan pandemi seperti saat ini, sarana umum beserta masyarakat harus selalu dijaga serta menjaga kebersihan dan kesehatannya. Oleh karena itu, dilakukannya kegiatan pembersihan masjid dan pembagian masker setiap hari Jumat di Masjid Jami Al-Ittihad Desa Labuhan Haji. 

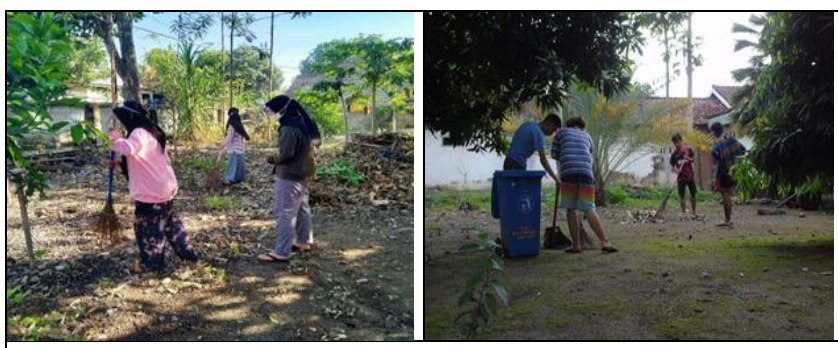

Gambar 18. Pembersihan Masjid Jami Al-Ittihad Desa Labuhan Haji

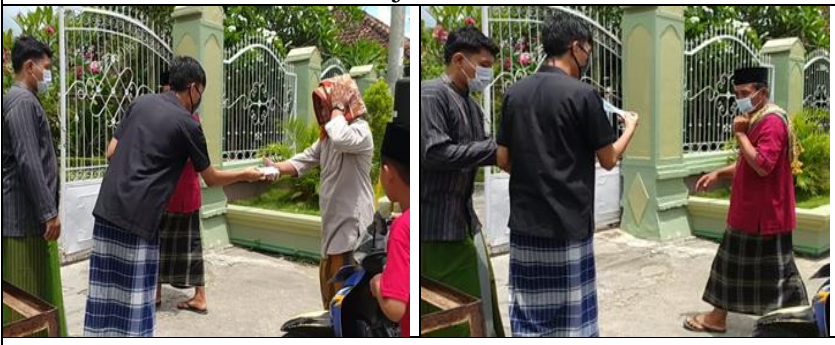

Gambar 19. Pembagian Masker di Masjid Jami AlIttihad Desa Labuhan Haji

\section{4) Pembuatan Label Produk UMKM}

Kemasan dan label dari suatu produk merupakan elemen yang sangat penting dalam penjualan dan pemasaran produk. Kami menyadari bahwa kemasan dan label dari beberapa produk pangan UMKM di Desa Labuhan Haji belum memenuhi standar tersebut.

Oleh karena itu, dilakukannya rebranding kemasan dan label dari beberapa produk pangan UMKM di Desa Labuhan Haji seperti kerupuk rumput laut, teh kelor, terasi udang, pilus rumput laut, dan dodol rumput laut dengan tujuan dan harapan agar produk-produk pangan tersebut layak dijual dan dipasarkan secara lokal, nasional maupun global. Selain itu, kelak ketika program TDC sudah dibangun di Desa Labuhan Haji, produk-produk pangan tersebut dapat menjadi produk unggulan dari Desa Labuhan Haji.

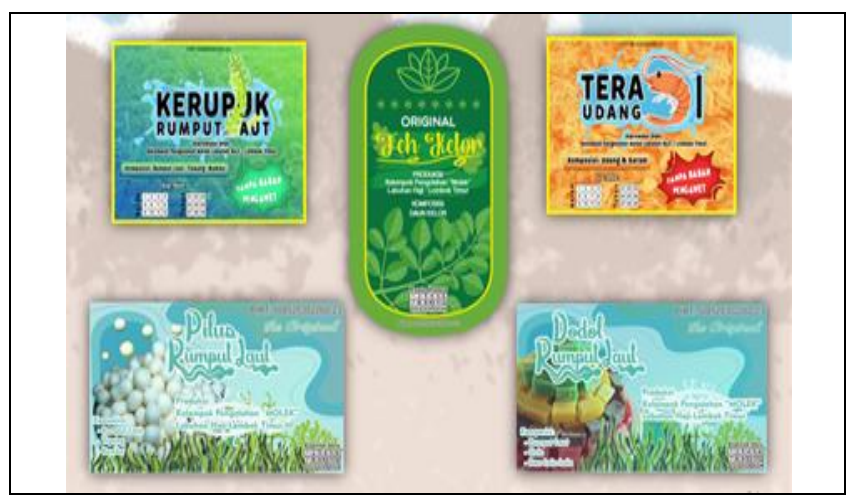

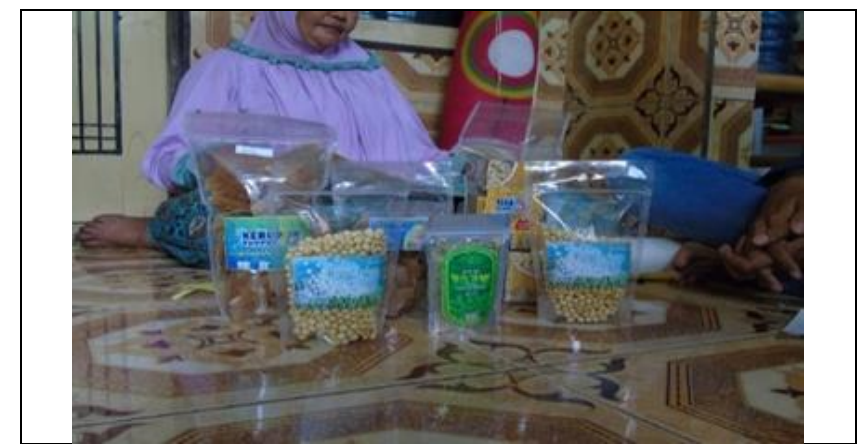

Gambar 20. Rebranding Kemasan dan Label Produkproduk Pangan UMKM Desa Labuhan Haji

\section{5) Pembuatan Bak Sampah dan Pembersihan Pantai}

Desa Labuhan Haji merupakan suatu desa yang dekat dengan pantai dan laut serta sangat berpotensi menjadi desa wisata. Namun, ketersediaan tempat pembuangan sampah yang masih jarang ditemui serta tingkat kesadaran masyarakat yang masih rendah akan pentingnya untuk menjaga kebersihan lingkungan menjadi salah satu penyebab pantai dan laut Desa Labuhan Haji menjadi cukup kotor dan kurang terawat.

Maka dari itu, dilakukannya small movement yaitu pembuatan bak sampah sebanyak 10 buah dan kegiatan pembersihan pantai bersama Pokdarwis Desa Labuhan Haji yang dilakukan pada minggu terakhir kegiatan KKN dengan tujuan dan harapan meningkatkan kesadaran masyarakat Desa Labuhan Haji untuk pentingnya menjaga kebersihan lingkungan sekitar sehingga kelak Desa Labuhan Haji dapat menjadi desa wisata dengan pengunjung dari lokal, nasional, hingga global.

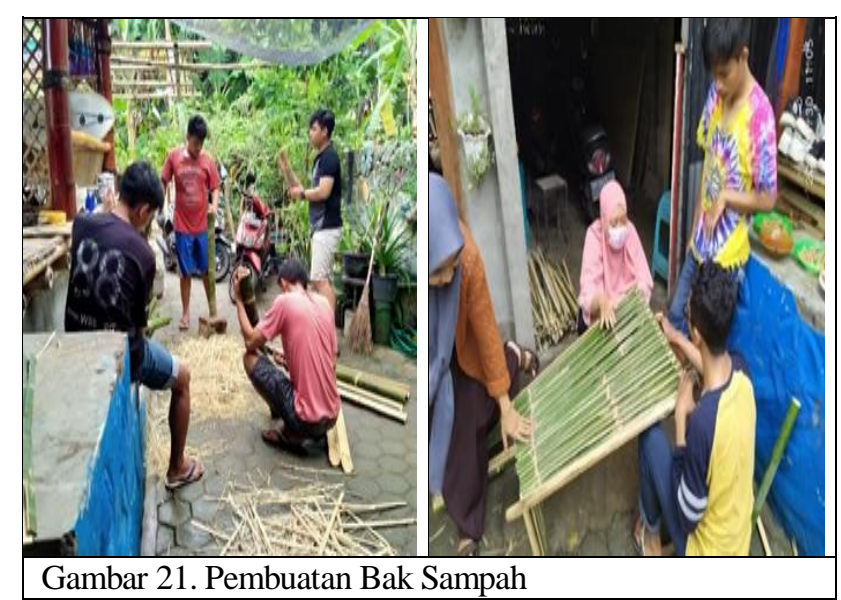




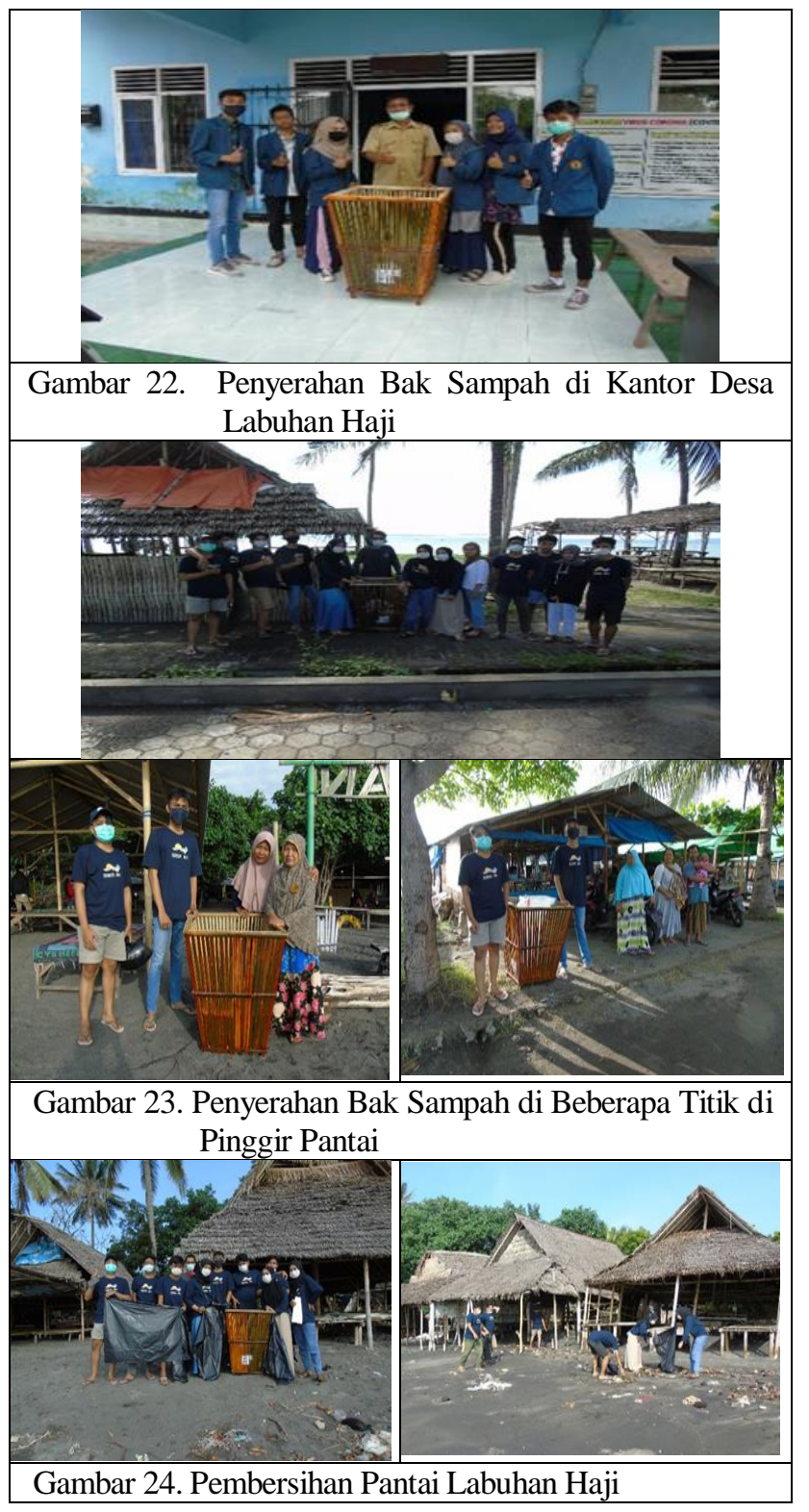

6) Konsultasi KKN dengan DPL

Melakukan kegiatan konsultasi dengan DPL bapak Dr. Drs. H. Ahmad Jupri, M.Eng untuk membahas terkait program-program kerja yang akan kami laksanakan di desa labuhan haji.

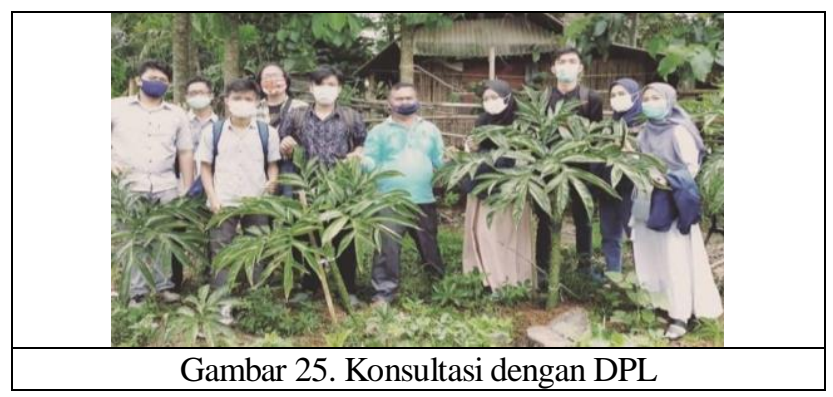

\section{Kesimpulan}

Program KKN Tematik di Era New Normal merupakan salah satu bentuk pengabdian kepada masyarakat yang dilakukan oleh mahasiswa sebagai salah satu wujud implementasi Tri Dharma Perguruan Tinggi, yang dipadukan pelaksanaan manajemen dan waktunya dengan kegiatan yang selalu memperhatikan protokol kesehatan disetiap kegiatan. Program Kuliah Kerja Nyata (KKN) yang bertemakan Mahadesa merupakan sebuah program untuk mensosialisasikan suatu program Mahadesa TDC (Trade Distribution Center) yaitu program infrastruktur ekonomi digital terintegrasi di NTB dalam mewujudkan sistem perdagangan berbasis teknologi digital di NTB. Desa Labuhan Haji adalah salah satu dari sekian banyak desa di Kecamatan Labuhan Haji, Kabupaten Lombok Timur, NTB yang sektor ekonominya terdampak pandemi Covid-19, khususnya UMKM dan pedagang warung. Sistem perdagangan berbasis teknologi digital ini diharapkan menjadi jembatan agar produk UMKM di Desa Labuhan Haji dapat mengakses pasar digital. Sehingga dapat mengurangi permasalahan di bidang ekonomi desa seperti dalam pendistribusian produk-produk UMKM desa, yang lingkup pendistribusiannya terbatas. Selain sosialisasi program Mahadesa TDC, juga dilakukan program kerja tambahan lainnya seperti, mengajar mengaji dan mengadakan beberapa lomba di TPQ, pembersihan masjid dan pembagian masker setiap hari Jumat, rebranding label dan kemasan beberapa produk pangan UMKM, pembuatan bak sampah dan pembersihan pantai.

\section{Ucapan Terima Kasih}

Kami mengucapkan terimakasih kepada Bapak Pahminuddin, selaku Kepala Desa Labuhan Haji, Bapak Saifuddin Zuhri selaku Sekretaris Desa Labuhan Haji, Bapak Yadin Amrullah selaku Kepala Urusan Desa Labuhan Haji, Bapak Dr. Drs. Ahmad Jupri, M.Eng. selaku dosen pembimbing lapangan, dan seluruh masyarakat yang ada di Desa Labuhan Haji serta semua pihak yang telah membantu selama kegiatan $\mathrm{KKN}$ berlangsung. 


\section{Daftar Pustaka}

Fathoni, Abdurrahman. 2006. Organisasi Dan Manajemen Sumber Daya Manusia. Jakarta: PT Rineka Cipta

Newman, W. Lawrence, 2013, Metodologi Penelitian Sosial: Pendekatan Kualitatif dan Kuantitatif (edisi 7), PT Indeks, Jakarta.

Mason, J. 2002. Qualitative Researching ( $2^{\text {nd }}$ Edition), Sage Publication, London.

Merriam, S.B. 2015. Introduction to Qualitative Research and Case Study. San Francisco, Josey-Bass Inc.

Taylor, S.J and Bogdan R. 2016. Introduction to Qualitative Research Methods: The Search for Meanings, A Wiley-Inter Science Publication, John Wiley and Sons, New York. 